\title{
Gastric adenocarcinoma of fundic gland type with two closely located lesions endoscopically resected en masse
}

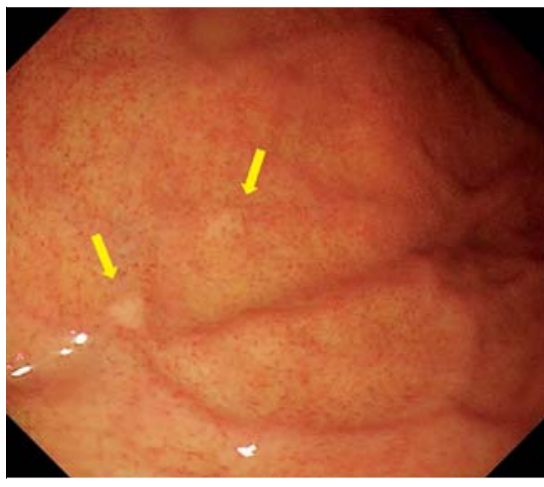

- Fig. 1 Endoscopic findings. In the greater curvature of the fornix, two small lesions were found adjacent to each other (arrows). Each was $<2 \mathrm{~mm}$ in diameter, whitish, and flat, with poorly defined borders. They were located $<1 \mathrm{~cm}$ apart.

A 73-year-old man with type 2 diabetes mellitus, but otherwise healthy, underwent esophagogastroduodenoscopy screening. The examination revealed red streaks and no atrophic mucosal areas. Therefore, Helicobacter pylori infection was not suspected. Two small lesions $<2 \mathrm{~mm}$ in diameter and located $<1 \mathrm{~cm}$ apart were observed in the fornix. Both lesions were similar: whitish and flat with poorly defined borders (\Fig.1). A biopsy from the anterior-sided lesion was diagnosed as gastric adenocarcinoma of the fundic gland type.

Endoscopic submucosal dissection was performed. The two closely located lesions were resected and included in a single surgical specimen ( $\triangleright$ Video 1 ). Histopathologically, carcinoma mimicking normal fundic glands with a pale basophilic cytoplasm and nuclei located basally infiltrated the deep layer of the lamina propria and had irregular branching structures ( $\mathbf{F i g . 2}$ ). The lesions had diffuse positivity for MUC6, focal positivity for $\mathrm{H}^{+} / \mathrm{K}^{+}$-ATPase, and negativity for MUC2, MUC5AC, CD10, and pepsinogen I. Both lesions were diagnosed as adenocarcinomas of the fundic gland type. The

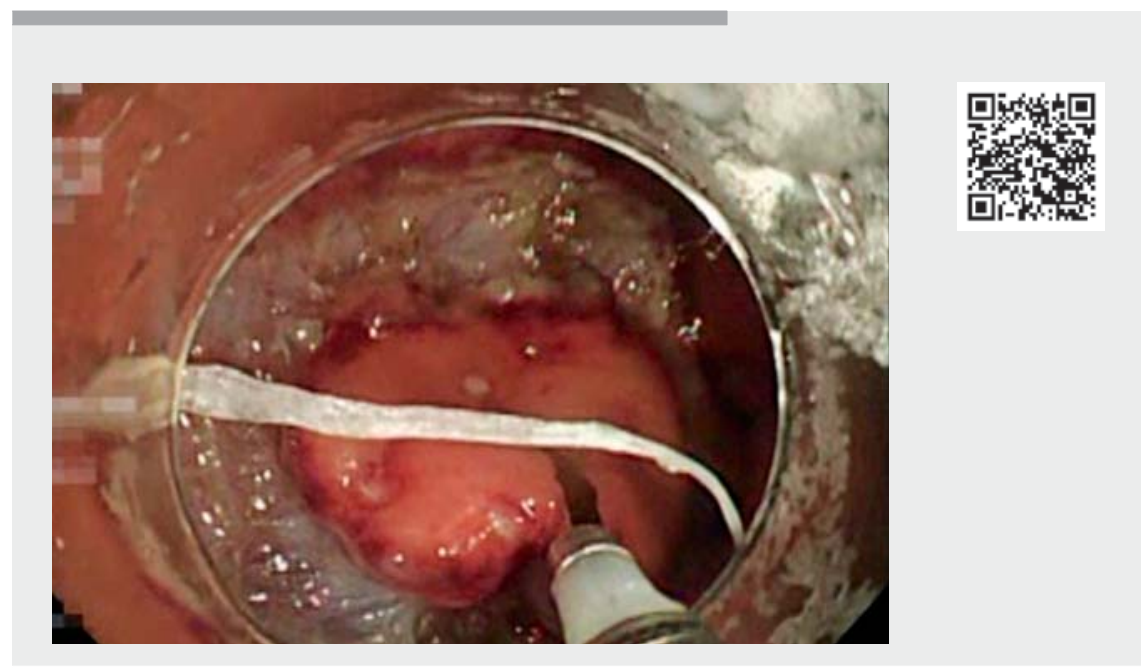

Video 1 The two closely located lesions were resected and included in a single surgical specimen.

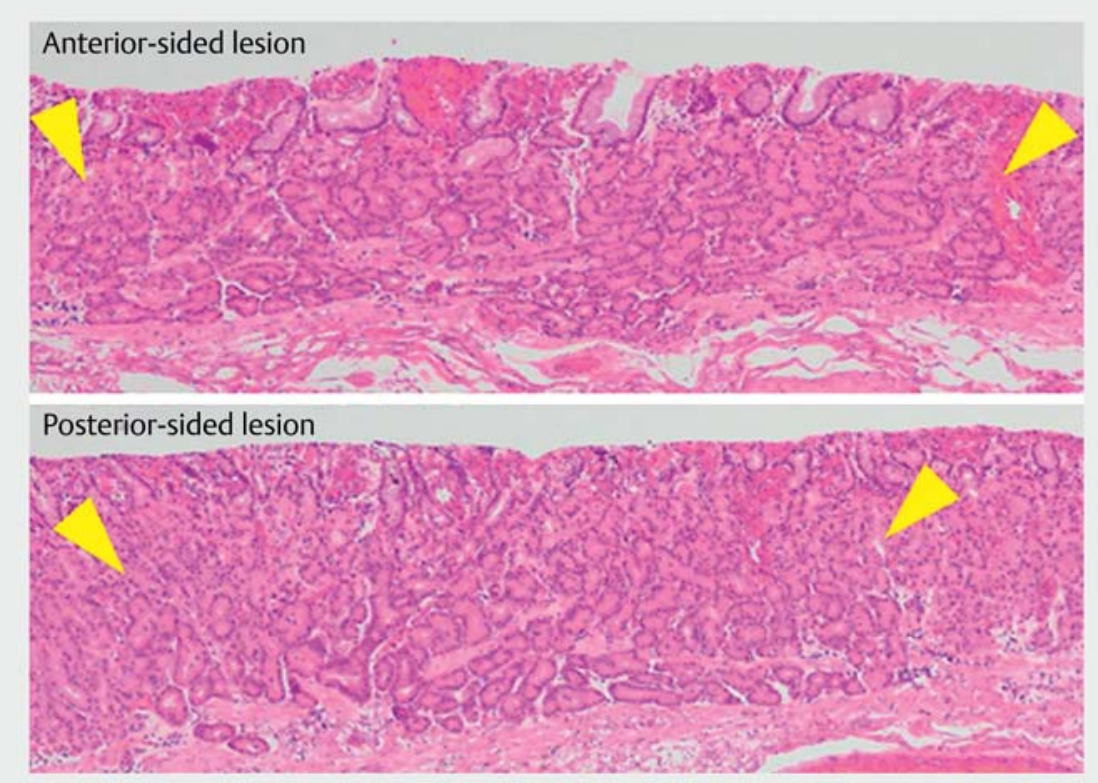

Fig. 2 Endoscopically resected specimens. The anterior-sided lesion was $1.6 \mathrm{~mm}$ in diameter and the posterior-sided lesion $1.3 \mathrm{~mm}$. Carcinoma mimicking normal fundic glands infiltrated the deep layer of the lamina propria; hematoxylin and eosin staining. 
patient did not present subsequent recurrence after 2 years.

Gastric adenocarcinoma of the fundic gland type, a novel entity of gastric adenocarcinoma proposed by Ueyama et al. [1], is commonly observed in elderly individuals and is located in the upper third of the stomach. It originates from the deep part of normal fundic glands without atrophy [2]. Most are solitary lesions; only three cases of multiple lesions have been reported thus far [3-5]. To the best of our knowledge, this is the first case of multiple such lesions located close enough to be endoscopically resected en masse. Multiple gastric adenocarcinomas of this type can arise extremely close together. Thus, the adjacent mucosa must be comprehensively examined before endoscopic treatment to prevent overlooking lesions, which may lead to the extent of resection being improper.

Endoscopy_UCTN_Code_CCL_1AB_2AD_3AB

\section{Competing interests}

The authors declare that they have no conflict of interest.
The authors

Tomohiko Mannami ${ }^{1}$, Takehiro Tanaka², Nobukiyo Fujiwara ${ }^{3}$

1 Department of Gastroenterology, National Hospital Organization Okayama Medical Center, Okayama, Japan

2 Department of Pathology, Okayama University Graduate School of Medicine, Dentistry, and Pharmaceutical Sciences, Okayama, Japan

3 Department of Internal Medicine, Chugoku Central Hospital, Fukuyama, Japan

\section{Corresponding author}

\section{Tomohiko Mannami, MD, PhD}

Department of Gastroenterology, National Hospital Organization Okayama Medical Center, 1711-1 Tamasu, Kita-Ku, Okayama 701-1192, Japan

Fax: +81-86-294-9255

tmannami-gi@umin.ac.jp

\section{References}

[1] Ueyama H, Yao T, Nakashima Y et al. Gastric adenocarcinoma of fundic gland type (chief cell predominant type): proposal for a new entity of gastric adenocarcinoma. Am J Surg Pathol 2010; 34: 609-619

[2] Ueyama H, Matsumoto K, Nagahara A et al. Gastric adenocarcinoma of the fundic gland type (chief cell predominant type). Endoscopy 2014; 46: 153-157

[3] Kino H, Nakano M, Kanamori A et al. Gastric adenocarcinoma of the fundic gland type after endoscopic therapy for metachronous gastric cancer. Intern Med 2018; 57: 795800

[4] Watanabe R, Yada T, Ikegami Y et al. A case of multiple gastric adenocarcinomas of fundic gland type. Prog Dig Endosc 2018; 92: 104-105

[5] Chen O, Shao ZY, Qiu X et al. Multiple gastric adenocarcinoma of fundic gland type: a case report. World J Clin Cases 2019; 7: 2871-2878

Bibliography

Endoscopy 2022; 54: E413-E414

DOI 10.1055/a-1559-2158

ISSN 0013-726X

published online 8.9.2021

(c) 2021. Thieme. All rights reserved. Georg Thieme Verlag KG, Rüdigerstraße 14, 70469 Stuttgart, Germany

\section{ENDOSCOPY E-VIDEOS}

https://eref.thieme.de/e-videos

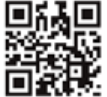

Endoscopy E-Videos is an open access online section, reporting on interesting cases and new techniques in gastroenterological endoscopy. All papers include a high quality video and all contributions are freely accessible online. Processing charges apply (currently EUR 375), discounts and wavers acc. to HINARI are available.

This section has its own submission website at https://mc.manuscriptcentral.com/e-videos 